\title{
Validity and Reliability Measurement of Bengali Translated Questionnaire for Urinary Incontinence Diagnosis
}

\author{
Shamima Islam Nipa, Ph.D. Candidate ${ }^{1}$, Thanyaluck Sriboonreung, Ph.D. ${ }^{1}$, Aatit Paungmali, Ph.D. , \\ Chailert Phongnarisorn, M.D. ${ }^{2}$, Md.Fazlul Karim Patwary, M.Sc. ${ }^{3}$
}

'Department of Physical Therapy, Faculty of Associated Medical Sciences, Chiang Mai University, Mueang, Chiang Mai 50200, Thailand.

2Department of Obstetrics \& Gynecology, Faculty of Medicine, Chiang Mai University, Mueang, Chiang Mai 50200, Thailand. ${ }^{3}$ Department of Information Technology, Jahangirnagar University, Savar, Dhaka, 1343, Bangladesh.

Received 1 December 2020 • Revised 4 February 2021 • Accepted 8 February 2021 • Published online 27 May 2021

\section{Abstract:}

Objective: The aim of this study was to translate and verify the validity and reliability of the Bengali translated questionnaire for Urinary Incontinence Diagnosis (QUID), to ensure the diagnosis of urinary incontinence in Bangladesh.

Material and Methods: Adaptation and psychometric properties testing of the Bengali-QUID were conducted with 67 respondents. Twenty respondents were included for pre-testing and adaptation; whereas, 47 respondents were considered for test-retest reliability. The content validity of the questionnaire was measured by expert opinion. Cornbach's alpha statistical test was used to measure the internal consistency of the questionnaire, while the test-retest reliability was measured using the Intra-Class Correlation $(2,1)$ model.

Results: Content validity for all items of the questionnaire was $>0.75$. In addition, the Cronbach's Alpha values for interitem correlation for Stress Urinary Incontinence and Urge Urinary Incontinence were $(\alpha>0.8)$ and $(\alpha>0.7)$, respectively. Furthermore, the reliability of the Bengali-QUID questionnaire had an Intra-class correlation score of 0.76.

Conclusion: This study demonstrated that the Bengali version of QUID questionnaire was highly valid, and reliable for diagnosis of urinary incontinence among Bangladeshi women.

Keywords: QUID, reliability, stress urinary incontinence, urinary incontinence, validity

Contact: Shamima Islam Nipa, Ph.D. Candidate Department of Physical Therapy, Faculty of Associated Medical Sciences, Chiang Mai University, Mueang, Chiang Mai 50200, Thailand.

E-mail: shamimamrs2017@gmail.com This is an open access article under the CC BY-NC-ND license (http://www.jhsmr.org/index.php/jhsmr/about/editorialPolicies\#openAccessPolicy).

J Health Sci Med Res 2022;40(1):19-26 doi: $10.31584 / j h s m r .2021813$ www.jhsmr.org 


\section{Introduction}

Urinary incontinence $(\mathrm{UI})$ is an involuntary leakage of urine. ${ }^{1}$ Worldwide; approximately $10.0 \%$ of adult women suffer from Ul. ${ }^{2}$ Among the three types of urinary incontinence, stress urinary incontinence is the most prevalent. Meanwhile, the other types; urge urinary incontinence and mixed urinary, incontinence increase with age. ${ }^{1}$

Since severity of urinary incontinence significantly affects the quality of life for women. Early detection and primary prevention are necessary to prevent negative consequences. There are numerous diagnostic and severity of urinary incontinence measurement questionnaires; however, very few of these assure cultural adaptation and reliability measures. Meanwhile, in respects of cultural context for Bangladesh, no measurement tool has been translated, nor have the psychometric properties been tested, as of yet.

UI can be measured either by invasive, noninvasive measurement or questionnaires. Among the several types of questionnaires, questionnaires for urinary incontinence diagnosis (QUID) is commonly used as a self-reporting approach. ${ }^{3}$ The QUID questionnaire is a 6-item questionnaire that is used to distinguish between stress urinary incontinence and urge urinary incontinence. ${ }^{4}$ However, the use of the English version amongst Bengali is difficult, and may generate inaccurate responses. Therefore, there is a need for translation the QUID questionnaire into a Bengali version, and to test the psychometric properties of the questionnaire for scientific use in Bangladesh. The findings would help in early detection and screening, for urinary incontinence among the women.

\section{Material and Methods}

The study was conducted at the Musculo-skeletal outpatient unit at the Centre for the Rehabilitation of the Paralyzed (CRP), Bangladesh from; December 2019 to March 2020. Twenty respondents were included for the pre-testing and adaptation of the Bengali-version of the
QUID questionnaire. In addition, this study included 47 respondents for the test-rest reliability. Considering the $80.0 \%$ effect size of intervention; the estimated sample size requiredwas $47 .{ }^{5}$ Permission to conduct the study was obtained from the ethical review committee at the CRP (CRP-R\&E-0401-280). A written informed consent form was obtained from all the respondents before participating in the study.

The inclusion criteria considered were women between 18-60 years of age, having urinary incontinence, and ability to read the Bengali language along with the willingness to participate in the study. The study excluded those women who had neurogenic bladder symptoms, pregnancy or at the post-partum period, and having urinary tract infections or pelvic floor surgery. Furthermore, the study also excluded those respondents' who were not willing to participate.

This QUID questionnaire is one of the most commonly used self-report questionnaires. The original English version of QUID was developed by Bradley, et al. ${ }^{3}$ It is a self-administered, 6-item questionnaire designed to distinguish between SUI and UUI. Each item scores: 0 (None of the time), 1 (Rarely), 2 (Once in a while), 3 (Often), 4 (Most of the time) or 5 (All of the time). Responses to items 1, 2 and 3 are summed for the Stress score; and responses to items 4,5 , and 6 are summed for the Urge score. ${ }^{4}$

The original English version of the QUID questionnaire was translated into the Bengali language as per the linguistic validation process of the Mapi research institute. ${ }^{6}$ This newly translated Bengali version of the questionnaire was tested for psychometric properties. The cross-cultural adaptation process was accompanied by six steps; including: (1) forward translation forward translation, (2) synthesis (3) back word translation, (4) expert committee review (5) pretesting of the translated version, and (6) submission of respective reports, forms and documents for appraisal, respectively. Details of the translation process are shown in (Figure 1). 


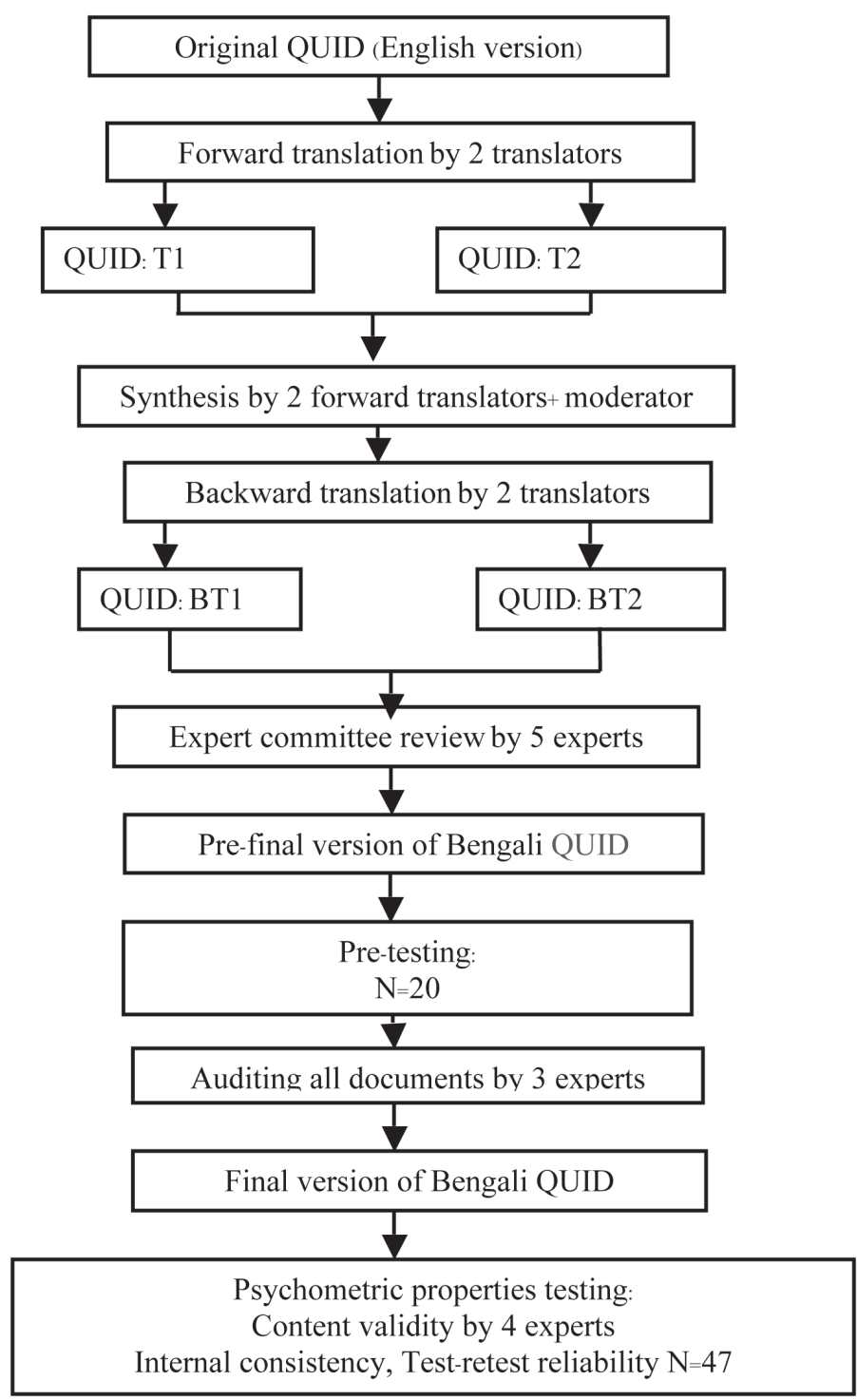

QUID=Questionnaire for Urinary Incontinence Diagnosis, T1=Forward Translator 1, T2=Forward Translator 2, BT1=Backward Translator 1, BT2=Backward Translator 2

Figure 1 Translation, adaptation and psychometric properties testing process

At the end of the translation process, the final version of the Bengali-QUID was tested for psychometric properties. The psychometric properties of the final version of the Bengali-QUID questionnaire were verified by the validity and reliability tests. In this study, content validity, internal consistency, and test-retest reliability were employed to verify the final Bengali version of QUID questionnaire. 
The content validity was evaluated by four experts from different departments; including: two clinical physiotherapists, a senior clinical physiotherapist, and a research monitoring and evaluation officer of CRP, so as to minimize bias.

A paper-based survey questionnaire was used to obtain data for internal consistency, and subjects were selected by a purposive sampling technique. The aim of this present study was to clearly explaine to the participants the study, and to ensure participation interest. Interested participants were asked to sign the consent form, and then rate the Bengali-QUID on a scale. Data from the BengaliQUID questionnaire were analysed for psychometric properties.

The reliability of the Bengali translated QUID questionnaire was conducted as a test measured over time. The test was repeated twice on the same patient in a one week interval. ${ }^{7}$ The internal consistency of the Bengali translated QUID questionnaire was measured based on the correlations between the different items of the QUID questionnaire on the same test. Based on a subjective approach to the 6-items QUID questionnaire ${ }^{8}$, several items of the QUID questionnaire, proposed to measure the type and severity of urinary incontinence, were compared for similar scores. The final version of the Bengali-QUID (paper-based form) was judged by four experts, and the professional's subjective judgment was used to rate the content validity score $(\mathrm{CVI}){ }^{9}$ The experts were requested to rate each item of the questionnaire based on a four-point scale indicating: relevance, clarity, simplicity, and ambiguity. Demographic characteristics of the respondents' were analysed through descriptive statistics using the Statistical Package of Social Sciences Software 20.0 version for data management. The internal consistency of the questionnaires was measured by Cornbach's alpha statistical test, while the Intra-Class Correlation $(2,1)$ model was used to measure the test-retest reliability.

\section{Results}

This present study included 20 respondents for the pre-testing of the pre-final version of Bengali translated Questionnaire for Urinary Incontinence Diagnosis. In addition, the study included 47 respondents for the testretest reliability of the Bengali version of the questionnaire. The data collector approached 52 women suffering with urinary incontinence to participate for the test-retest reliability; from which 47 participants' responded (response rate $90.0 \%$ ). The mean age of respondents was 41.4 (IQR; 11); standard deviation (S.D.) \pm 9.90 years. The majority of respondents were housewives (61.7\%). Approximately, $76.6 \%$ of these women lived in urban areas, with $23.4 \%$ having a secondary education. The socio-demographic status of the women with urinary incontinence is presented in Table 1.

Table 1 Socio-demographic characteristics of the respondents

\begin{tabular}{lll}
\hline Characteristics & Number & $\%$ \\
\hline Occupation & & \\
$\quad$ Housewife & 29 & 61.7 \\
Service holder & 4 & 8.5 \\
Teacher & 11 & 23.4 \\
Garments worker & 3 & 6.4 \\
Living place & & \\
Urban & 36 & 76.6 \\
Semi-urban area & 9 & 19.1 \\
Rural area & 2 & 4.3 \\
Educational status & & \\
Primary & 10 & 21.3 \\
Secondary & 11 & 23.4 \\
SSC passed & 10 & 21.3 \\
HSC passed & 3 & 6.4 \\
Honors & 6 & 12.8 \\
Masters & 7 & 14.8 \\
\hline
\end{tabular}

SSC=Secondary School Certificate $\mathrm{HSC}=$ Higher Secondary School Certificate 
The study revealed that none of the 20 respondents had any comprehensive or conceptual difficulties for questions 1 to 4 throughout the adaptation process of the Bengali version of the QUID questionnaire. On the contrary, approximately $55.0 \%(n=11)$ of respondents faced conceptual difficulties for question no. 5: "Do you get such a strong and uncomfortable need to urinate that you leak urine (even small drops), or wet yourself before reaching the toilet?" In addition, $27.0 \%(n=5)$ experienced conceptual difficulties for question no. 6: "Do you have to rush to the bathroom because you get a sudden, strong need to urinate?" The majority of the respondents faced conceptual difficulties to understand the $5^{\text {th }}$ and $6^{\text {th }}$ questions as these questions were extended, and alienated into several parts. Therefore, the instructor explained the concepts of both questions to the respondents to aid them in their answers. For easier understanding, the questions were altered and amended as: "Does your urine go out due to the intense and uncomfortable urge to urinate?" In addition to: "Do you have to go to the bathroom quickly because of a sudden urine pressure?
Each item of the QUID questionnaire had a score higher than 0.75 . Table 2 presents the CVI of each item of the questionnaire, as per the experts' opinion.

Items 1 to 3 of the questionnaire are used to diagnosis SUI; whereas, items 4 to 6 are considered in the diagnosis of UUI. The study results showed a correlation among all the items of the SUI diagnosis of the questionnaire, as demonstrated by the Cronbach's Alpha $(\alpha=0.838 ; \alpha=0.819 ; \alpha=0.815)$, respectively. In addition, the UUI score revealed an internal consistency of items 4 to 6 in the questionnaire, as demonstrated by the Cronbach's Alpha ( $\alpha=0.727 ; \alpha=0.721 ; \alpha=0.728)$, respectively. The internal consistency of the QUID questionnaire is presented in Table 3.

Among the 47 respondents; $68.0 \%$ were suffering from stress urinary incontinence, while $32.0 \%$ were suffering from urge urinary incontinence. The mean scores for SUI and UUI were 3.91;S.D. \pm 2.74 (IQR;3) and 2.85;S.D. \pm 4.75 (IQR;6), respectively. The test-retest reliability score of the Bengali-QUID questionnaire is presented in Table 4.

Table 2 Content validity of the Questionnaire for Urinary Incontinence Diagnosis

\begin{tabular}{ll}
\hline Item of QUID questionnaire & Obtained score $(\mathbf{C V I})$ \\
\hline Q1. When you cough or sneeze? & $1(>0.75)$ \\
Q2.When you bend down or lift something up? & $1(>0.75)$ \\
Q3. When you walk quickly, jog or exercise? & $1(>0.75)$ \\
Q4. While you are undressing in order to use the toilet? & $0.93(>0.75)$ \\
Q5.Do you get such a strong and uncomfortable need to urinate that you leak urine (even small drops) or & $0.81(>0.75)$ \\
wet yourself before reaching the toilet? & $0.87(>0.75)$ \\
Q6. Do you have to rush to the bathroom, because you get a sudden, strong need to urinate?
\end{tabular}

QUID=Questionnaire for Urinary Incontinence Diagnosis, CVI=content validity index 
Table 3 Internal consistency of the Questionnaire for Urinary Incontinence Diagnosis questionnaire

\begin{tabular}{|c|c|c|c|c|c|}
\hline Statistics for scale & & $\begin{array}{l}N \\
6\end{array}$ & $\begin{array}{l}\text { Mean } \\
6.76\end{array}$ & $\begin{array}{l}\text { Variance } \\
39.22\end{array}$ & $\begin{array}{l}\text { S.D. } \\
6.26\end{array}$ \\
\hline Item-total statistics & $\begin{array}{l}\text { Scale mean if } \\
\text { item deleted }\end{array}$ & & $\begin{array}{l}\text { Corrected } \\
\text { item-total } \\
\text { correlation }\end{array}$ & & $\begin{array}{l}\text { Cronbach's } \\
\text { alpha if item } \\
\text { deleted }\end{array}$ \\
\hline Item 1 & 3.7872 & & 0.312 & & 0.838 \\
\hline Item 2 & 6.4255 & & 0.382 & & 0.819 \\
\hline Item 3 & 6.1702 & & 0.404 & & 0.815 \\
\hline Item 4 & 5.9149 & & 0.795 & & 0.727 \\
\hline Item 5 & 5.8723 & & 0.816 & & 0.721 \\
\hline Item 6 & 5.6596 & & 0.782 & & 0.728 \\
\hline
\end{tabular}

Table 4 Test-retest reliability of the Bengali translated Questionnaire for Urinary Incontinence Diagnosis questionnaire

\begin{tabular}{|c|c|c|c|c|c|c|c|}
\hline & \multirow{2}{*}{$\begin{array}{l}\text { Intra-class } \\
\text { correlation }\end{array}$} & \multicolumn{2}{|c|}{$95 \%$ confidence interval } & \multicolumn{4}{|c|}{$F$ test with true value 0} \\
\hline & & Lower bound & Upper bound & Value & df1 & df2 & Sig \\
\hline Average Measures & 0.760 & 0.624 & 0.855 & 4.162 & 46 & 138 & 0.000 \\
\hline
\end{tabular}

\section{Discussion}

The adverse effects of urinary incontinence are increasingly recognized. Early detection of urinary incontinence, types and severity measures are important factors to prevent poor quality of life among women with urinary incontinence. Hence, this study aimed to assess the validity and reliability of a Bengali translated questionnaire for diagnosis of Urinary Incontinence (QUID). The study affirmed that the content validity of each item of the Bengali-QUID questionnaire was $>0.75$. Nevertheless, the $5^{\text {th }}$ and $6^{\text {th }}$ questions, with scores of 0.81 and 0.87 , were revised according to the experts' opinion. The Bengali-QUID questionnaire would ensure the diagnosis of urinary incontinence, as stated by a previous study, in that interpretation of the results measured by the content validity is precise.

Previously, the QUID questionnaire validated in the Malay language in Malaysia noted that thethe QUID research instrument is a diminutive, valid, and amenable instrument to distinguish between the types of urinary incontinence. ${ }^{10}$ The 0.76 reliability value of the Bengali version of the QUID questionnaire is supported by previous reliability tests; as shown by the 0.753 Cronbach's alpha coefficient for the English language QUID, and $0.823 .{ }^{10}$ Comparison with a previous study showed that the Malay language QUID was better than the English language QUID for diagnosing the types of urinary incontinence. ${ }^{11}$ Very recently, a validated QUID-Thai version was judged valid and reliable, as to the original English version. ${ }^{12}$ The study illustrated that the QUID was favourable to ensure diagnosis, and would be utilized in urology or gynecology clinical practice, primary health care settings and epidemiological trails in Thailand. ${ }^{12}$ Furthermore, a Chinese version of the QUID questionnaire indicated psychometric properties with test-retest reliability of $(k=0.79)$ and criterion validity of $(k=0.62)$, respectively. The study concluded that the QUID-Chinese version was a 
reliable and valid questionnaire for the diagnosis of urinary incontinence among Chinese women. ${ }^{13}$ The clinical findings of this present study was in line with the previous study stating that the SUI score was higher than the UUI score among the respondents, as per the QUID questionnaire. ${ }^{14}$ To date, there is no valid and reliable Bengali translated QUID questionnaire for diagnosing the types of urinary incontinence. Therefore, this questionnaire would assist in the early detection of types of urinary incontinence, and measurement of urinary incontinence severity. Furthermore, the findings of this study could be used as a follow-up intervention tool to measure the patient's improvement.

The strength of the study is the objectives were clearly stated. Consequently, the process of translation and psychometric property testing, including the flowchart of the process, were defined. However, this study did not test the psychometric properties of responsiveness for surgical treatment, nor pathological or neurological conditions.

\section{Conclusion}

The Bengali-version of the QUID questionnaire could be adopted for diagnosis of types of urinary incontinence in Bangladesh. All items of the questionnaire were culturally adaptive, valid, and reliable to evaluate the definite types of urinary incontinence in Bangladesh.

\section{Acknowledgement}

The authors acknowledge all the respondents for their voluntary participation in this study.

\section{Conflict of interest}

There is no potential conflict of interest to declare.

\section{References}

1. Milsom I. The prevalence of urinary incontinence. Acta Obstet Gynecol Scand 2000;79:1056-9.

2. Irwin DE, Kopp ZS, Agatep B, Milsom I, Abrams P. Worldwide prevalence estimates of lower urinary tract symptoms, overactive bladder, urinary incontinence and bladder outlet obstruction. BJU Int 2011;108:1132-8.

3. Bradley CS, Rovner ES, Morgan MA, Berlin M, Novi JM, Shea JA, Arya LA. A new questionnaire for urinary incontinence diagnosis in women: development and testing. American $J$ Obst Gynecol 2005;192:66-73.

4. Bradley CS, Rahn DD, Nygaard IE, Barber MD, Nager CW, Kenton KS, Siddiqui NY, Abel RB, Spino C, Richter HE. The questionnaire for urinary incontinence diagnosis (QUID): validity and responsiveness to change in women undergoing nonsurgical therapies for treatment of stress predominant urinary incontinence. Neurourol Urodyn 2010;29:727-34.

5. Coe R. It's the effect size, stupid. British Educ Res Assoc Annual Conf 2002;12:14.

6. Varni JW. Linguistic validation of the PedsQLTM-A quality of life questionnaire [homepage on Internet]. Lyon: Mapi Research Institute; 2002 [cited 2012 Jun]. Available from: http://www.pedsql.org/translations.html

7. Irwin DL, Lass NJ, Pannbacker M, Koay ME, Whited JS. Clinical research methods in speech-language pathology and audiology. $3^{\text {rd }}$ ed. San Diego, CA: Plural Publishing; 2019.

8. Lyubomirsky S, Lepper HS. A measure of subjective happiness: Preliminary reliability and construct validation. Soc Indic Res 1999;46:137-55.

9. Lukitasari M, Hasan R, Handika J, Primiani C, Pujiati P, Dewi NK, Widiyanto W, Murtafiah W. Content validity study: instrument development to measure professional learning communities through lesson study. Int Conf Math Scie Educ 2018;3:75-8

10. Dhillon HK, Zaini MZ, Quek KF, Singh HJ, Kaur G, Rusli BN. Exploratory and confirmatory factor analyses for testing validity and reliability of the malay language questionnaire for urinary incontinence diagnosis (QUID). Open J Prevent Med 2014;4:844

11. Botlero R, Davis SR, Urquhart DM, Shortreed S, Bell RJ. Agespecific prevalence of, and factors associated with, different types of urinary incontinence in community-dwelling Australian women assessed with a validated questionnaire. Maturitas 2009;62:134-9.

12. SasivimolS, ChailertPh. Validation of the questionnaire for urinary incontinence diagnosis-Thai version [QUID-Thai 
version]. J Med Assoc Thai 2018;101:1251-4.

13. Li CY, Zhu L, Lang JH, Xu T, Shi XW. Exploratory and confirmatory factor analyses for testing validity and reliability of the Chinese language questionnaire for urinary incontinence diagnosis. Zhonghuafu Chan Kezazhi 2016;51:
$357-60$.

14. de Araujo CC, Juliato CR, de Andrade Marques A, Reis A, Brito LG. Validation and cultural translation for the Brazilian Portuguese version of the Questionnaire for Urinary Incontinence Diagnosis. Int Urogynecol J 2020;1:1-6. 